modifications incorporating game theory or bounded rationality are no different.

These methods have largely failed, and it was discovered that the five great periods of biological extinction, the inventory of failed multinational companies, and phenomena as diverse as stock-market crashes, biological phenomena and the structure of contacts on the World Wide Web are described by a 'power law'. Clearly, deeper forces are at work. In a power law, the frequency of an event falls away with the square of its size. These causal factors emerge not from outside perturbations, but from the intrinsic dynamics of highly interconnected networks that are far from equilibrium. The fascinating generic behaviour of these networks and the generation of complex behaviour from the iteration of simple rules has been beautifully described by Stuart Kauffman and Stephen Wolfram. So it is a shame that Ormerod does not discuss how the invisible hand of emergent network behaviour makes its presence felt.

There are some gems nevertheless, and the scale and breadth of Ormerod's analysis deserves commendation. Most interesting is the way in which power laws challenge conventional notions of causality. The stockmarket crash of September 1987, for example, in which the Dow Jones index collapsed by $20 \%$ in a single day, may not ultimately have had a distinct cause, as catastrophic events may occasionally have insignificant causes. More important, within Ormerod's framework, successful institutions evolve organically, indicating that excessive government intervention may be both unnecessary and counterproductive.

Adrian Woolfson is at the University of Cambridge, School of Clinical Medicine, Addenbrooke's Hospital, Hills Road, Cambridge CB2 2SP, UK

\title{
Politics and disease
}

Twenty-First Century Plague: The Story

of SARS

by Thomas Abraham

Johns Hopkins University Press: 2005.

176 pp. $\$ 24.95$

\section{Adrian Sleigh}

As a new and lethal disease caused by a previously unknown virus, severe acute respiratory syndrome (SARS) was the first speciesjumping global epidemic this century, and will not be the last. This slim book puts SARS in context with an opening chapter on emerging infections, and ends with one that considers the looming threat of pandemic influenza.
Twenty-First Century Plague is an accurate and intriguing account of the complexities of the SARS story, the interacting political responses and the underlying bioepidemiology, involving primarily China, Hong Kong and the World Health Organization (WHO). Written by Thomas Abraham, a journalist based in Hong Kong, the book focuses on the main players. We get a ringside seat to an accessible, well-referenced account of the science, the politics and the people involved.

The SARS story begins in China, and Abraham starts by illuminating the least-known aspect - what happened in Guangdong from November 2002 to March 2003. That was when the infection moved slowly from rural towns to the provincial capital before quickly spreading out from the province to the rest of China, Hong Kong and much of the world.

This is what we could not know when Chinese officials hid the facts despite incessant internal and external enquiries from the public, media, health agencies, governments and the WHO. At last, we learn how SARS first appeared and spread inside Guangdong, and how the local health system responded, with many examples of professional dedication, clinical excellence, intelligent investigation and selfless behaviour. Guangdong doctors produced excellent guidelines on diagnosis, treatment, hospital infection control and quarantine as early as 23 January 2003 - six weeks before the global emergency erupted. This information could have prevented thousands of infections but was not shared, even within China. Abraham gives us an excellent and dispassionate account of the cultural and political background to the cover-up, and the unfortunate consequences, both epidemiologically and politically, for China. There are lessons for everyone, as all governments could be tempted to cover up infection outbreaks, especially if the rest of the world cuts off social and economic contact. Transparency was the only solution for SARS, and eventually China paid a high price for its initial secrecy.

Subsequent chapters cover more familiar ground: the introduction of the disease to Hong Kong through an infected doctor visiting from Guangdong; explosive local transmission in several hospitals and a high-rise housing complex; and the spread to Singapore, Vietnam, Canada, Beijing and Taiwan. We also learn about the hunt for the virus and the crucial role of the WHO in inducing international collaboration and steering the global control efforts for this terrifying epidemic.
IMAGE
UNAVAILABLE FOR COPYRIGHT REASONS


We see the costs and benefits of our globalized world - at higher risk, but mobilizing faster and more smartly than ever before. This was the first 'digital' response to a lethal global epidemic: there were many examples of new digital tools, such as some excellent caseinformation and geographical contact-tracing systems devised in Hong Kong and a secure Internet-linked laboratory network mounted by the WHO.

Discovering and characterizing the causal virus and developing diagnostic tools transformed the global battle against SARS, and was done faster than for any previous infection. The tension created by simultaneous competition and collaboration among scientists chasing the virus, and the balance needed between excessive caution and reckless haste, are well described. This makes the virus hunt one of the most fascinating aspects of the SARS story. There were false leads and bad luck with initial culture attempts, but eventual success for several groups. Hong Kong University came out just ahead in the international race to identify the causative agent, and its findings were validated by others within a few hours. This satisfactory scientific outcome contrasts with that experienced by the hapless young Chinese scientists who seem to have discovered the virus several weeks earlier but could not reveal their findings because they would have contradicted incorrect statements made by their superiors - yet another price paid by China for its initial management of SARS.

The role played by the WHO is also an excellent story by itself. A small team based in Geneva, Manila, China and Vietnam collaborated to provide the global and regional leadership needed, and the results were excellent. We find out how difficult the task was involving political skill, judgement and courage. It is clear that the WHO in 2003 had just the right people to meet the SARS challenge. Unfortunately, we cannot be assured that such resolve or skill will appear next time, and this is one of the more sobering lessons from SARS. If left chronically underfunded, as in the past, the WHO may not have the staff and vigilance needed next time a comparable challenge arises.

I commend this book to those with an interest in emerging infections, SARS and China. Adrian Sleigh is at the National Centre for Epidemiology and Population Health, Australian National University, Canberra 0200, Australia.

\section{The power of collecting}

\section{Trading the Genome \\ by Bronwyn Parry \\ Columbia University Press: 2004. 352 pp. $\$ 39.50, £ 25.50$}

\section{Brendan Tobin}

The collection, control and commodification of biological resources, historically seen as the common heritage of humanity, have long had a role in the efforts of nations to build and maintain their economic and political power. One of the earliest and most ambitious projects of this sort was the proposal made to Britain's King George III to transplant breadfruit from Tahiti to serve as a source of food for slaves in the West Indies. A mutiny on the ship chosen to transport the plants - the Bounty quickly brought to an end the first major statesupported attempt by the scientific community to relocate economic plants.

More recently, advances in biotechnology and information technology have transformed the processes involved in the collection, transport and storage of biological resources and the information they contain. A new surge in collection in the 1980s was fuelled by improvements in the ability to isolate compounds from plants and animals, coupled with regulatory mechanisms enabling patents to be obtained over them. This time, however, developing countries, the primary source of biological resources, strongly resisted what some saw as biocolonialism. The United
Nations Convention on Biological Diversity (CBD) of 1992 was intended to respond to this conflict and ensure the equitable sharing of benefits derived from the access to, and use of, genetic resources. But the convention has so far had only limited success, and at the World Summit for Sustainable Development in Johannesburg in 2002, calls were made for the negotiation of an international regime on access and benefit sharing (ABS).

The history of biodiversity collection, and the transformation and commodification of genetic material, is the subject of Trading the Genome by Bronwyn Parry. Reviewing both the technological and the regulatory history of the gene trade, Parry's book provides insight into the complex problems facing the global community in regulating the access to, and the use of, genetic resources. With negotiations for the development of an international ABS regime due to begin in earnest in January 2006 in Spain, this publication is particularly timely.

Focusing her research on a number of key US initiatives, including those involving the National Cancer Institute and the US pharmaceutical industry, Parry reviews their collection, research and product-development practices, and long-term objectives. She persuasively argues that the end of large-scale bioprospecting is drawing close. Ever more sophisticated means of synthesizing and replicating collected material, as well as of mining both living and dried specimens in ex situ collections, will remove the need for much in situ bioprospecting. And combinatorial chemistry will replace the need to find resources in the wild.

Refreshingly, Parry contests the frequently posited position that combinatorial chemistry is free of all benefit-sharing obligations, and notes the need to close the legal loophole regarding pre-CBD collections. One key conclusion is the need to develop effective means of tracing the many and extensive uses of genetic resources and derived informational products. Unfortunately, her study does not refer to the work of the CBD in this area, in particular to the ongoing study of the practicalities, feasibility and cost of certificates of origin as a means of tracing the flow of genetic resources. I would also have liked to see more in-depth analysis of potential technological means of responding to the challenges of resource transformation and the monitoring of direct and indirect uses of genetic information.

Parry comes to the conclusion that further efforts to secure regulatory control are misplaced, suggesting instead that countries should seek alternative benefit-sharing mechanisms. She also suggests the establishment of an international trust for benefit sharing, an idea that is to some extent akin to the model included in the recently adopted International Treaty on Plant Genetic Resources for Food and Agriculture of the United Nations Food and Agriculture Organization. However, her failure to expand on this area of research and place it within the context of the ongoing ABS negotiation process weakens the value of what could have been a more substantial and reasoned proposal.

Overall, however, the book is a welcome addition to the literature and will be a valuable resource for researchers, decision-makers and members of the public who are interested in understanding what happens to genetic resources after they have been collected. It will provide little in the way of policy insight for veterans of the bioprospecting debate, but its organized presentation of the transformation of the bioprospecting trade and of the development of bioinformatics is well worth the read. However, its conclusions need to be considered in the light of recent developments. Among these are efforts by developed countries to adopt so-called 'user measures' to regulate the use of imported genes; debates in the CBD, the World Intellectual Property Organization and the World Trade Organization on proposals to include obligations to disclose the origin of genetic resources in patent applications; and work examining the feasibility, practicality and cost of mechanisms, such as certificates of origin to track flows of genetic resources, as described in a United Nations University report (www.ias.unu.edu/binaries/ UNUIAS_UserMeasures_2ndEd.pdf). Brendan Tobin is at the Institute of Advanced Studies, United Nations University, Nishi-ku, Yokohama 220-0012, Japan. 